\title{
Do we really need a surgery for hip fractures in elderly patients? Mortality rate and influencing factors
}

\author{
Kyu-Tae Hwang ${ }^{1}$, Jun-Ki Moon ${ }^{2}$ and Young-Ho Kim²
}

\begin{abstract}
Background: Hip fractures are associated with notable mortality rates in elderly patients. The purpose of the study was to evaluate the mortality rate and influencing factors associated with mortality in the elderly patients with hip fractures.

Methods: Between October 2000 and December 2009, 807 elderly patients with hip fractures were enrolled in this study. There were 197 men and 610 women. The mean age at injuries were 78 years (range, 65-99 years). The fractures consisted of 390 femoral neck fractures and 417 intertrochanteric fractures. The mortality rate was evaluated between patients who underwent surgical and nonsurgical treatments. The influencing factors associated with mortality rate were evaluated statistically.
\end{abstract}

Results: Overall, 691 (85.6\%) patients treated surgically and 116 (14.4\%) patients treated nonsurgically were included. The overall mortality rates one and two years after injuries were 16.6 and $39.4 \%$, respectively. In surgical treatment group, the mortality rate one and two years after injuries were 12.0 and $35.7 \%$, respectively. In nonsurgical treatment group, the mortality rates were 44.0 and $61.2 \%$, respectively $(p<0.05)$. No significant difference was noted between the types of fractures and the time from injury to surgery. Regardless of surgical methods, a significantly higher mortality rate was observed in patients with heart disease, chronic renal disease, dementia, and cancer, or in patients with 3 or more comorbidities.

Conclusions: In elderly patients with hip fractures, surgical treatments can decrease the mortality rate as compared with nonsurgical treatments. In addition, patients who had three or more comorbidities (heart disease, chronic renal failure, dementia, and history of cancer) are associated with a higher risk of mortality.

Trial registration: Retrospectively registered.

Keywords: Elderly, Hip fracture, Mortality rate, Influencing factor

\section{Introduction}

The incidence of hip fractures in elderly patients is increasing as population ages [1]. Hip fractures are associated with notable morbidity and mortality in elderly patients. A recent epidemiological study showed that the proportion of patients with severe comorbidity increased from 10 to $19 \%$ between 1980 and 2014 [2]. In a 5-year period from 2010 through 2014, the standardized 30-day mortality rate and 31 to 365-day mortality

\footnotetext{
* Correspondence: kimyh1@hanyang.ac.kr

${ }^{2}$ Department of Orthopedic Surgery, Hanyang University Guri Hospital, Gyomoon-dong 249-1, Guri city, Gyunggi-do 471-701, South Korea Full list of author information is available at the end of the article
}

rate were 10.55 and $19.28 \%$, respectively. There are many factors that influence the mortality rate after hip fractures. Paksima et al. [3] stated that the mortality rate after hip fractures is related to patient's age, ASA (American Society of Anesthesiologists) grades, postoperative complications, cancer history, chronic obstructive pulmonary disease, congestive heart failure, pre-injury ambulatory ability, and so on.

After hip fractures, most patients undergo surgery to reduce pain, to facilitate earlier ambulation, and to minimize complications, but some patients have nonsurgical treatments because of their medical condition and comorbidities [4]. Many studies have reported that the 
mortality rate after hip fracture was associated with various factors, but most studies were based on patients undergoing surgical treatment. There is little information regarding patients who received nonsurgical treatment.

In this retrospective study, we included all hip fractures regardless of treatments to evaluate the mortality rate and the influencing factors that affect mortality rates of the elderly patients one and 2 years after injury.

\section{Materials and methods}

Among patients over the age of 65 who visited our institute for hip fracture between October 2000 and December 2009, 807 patients were evaluated after exclusion of multiple trauma and previous history of hip disease. There were 197 male $(24.4 \%)$ and 610 (75.6\%) female patients. The mean age at the time of injuries was 78 years (range, 65-99 years). The hip fractures consisted of 390 femoral neck fractures and 417 intertrochanteric fractures. The Statistics Korea (a governmental project of the Republic of Korea) was used to obtain precise data of mortality. Other medical data, in addition to survival and death rates, were analyzed retrospectively.

The patients were divided into a surgical group and a nonsurgical group to investigate the mortality rates one and 2 years after fractures. The patients of surgical group were treated with open reduction and internal fixation or hemi-arthroplasty. The patients who refused the recommended surgeries were allocated in nonsurgical group and treated with bed rest using an abduction brace. The age, sex, surgery, types of fracture, surgical method, time from injury to surgery, ASA grades, smoking history, types and number of comorbidities, and types of medical insurance in the patients were collected to assess the mortality-influencing factors.

Based on patient age, the patients were divided into a group of patients younger than 75 years of age, a group of patients aged between 75 and 85 years, and a group of patients older than 85 years of age. Based on the type of fractures, the patients were divided into femoral neck fracture group and intertrochanteric fracture group. Based on the surgical techniques, the patients were divided into hemi-arthroplasty group and internal fixation group. Based on the time interval from injury to surgery, the patients were divided into a group within 5 days and a group after 5 days. Based on ASA grades, patients were divided into a lower-grade group (I, II) and a highergrade group 66 (III, IV). The underlying diseases such as congestive heart failure, ischemic heart disease, dementia, chronic kidney disease, hypertension, diabetes, chronic obstructive pulmonary disease, cancer, liver cirrhosis, rheumatoid arthritis, and Parkinson's disease were also allocated. Based on the number of comorbidities, the patients were divided into $0-2$ comorbidities group and 3 and above comorbidities group. Based on patient's medical reimbursement coverages, the patients were divided into medical insurance group and national medical care group. The national medical care refers to the policy issued by the Korean government for protection of patients with low incomes, which provides basic treatments, surgeries, medicines, and hospital transfer for free. Medical insurance is a co-pay system priced at a percentage of patient's salary. It covers every patient residing in Korea by paying a portion of medical cost.

SPSS 16.0 statistical software (IBM Corp, Armonk, NY USA) was used for analysis. Kaplan-Meier survival analysis was used for comparison and analysis of the mortality rates after fractures in both surgical and nonsurgical groups, and a chi-squared test and multivariate logistic regression were performed. A $p$ value $<0.05$ was considered to show statistical significance.

\section{Results}

There were 691 patients (85.6\%) who underwent surgical treatments, and the remaining 116 patients $(14.4 \%)$ had nonsurgical treatments including some patients who refused surgical treatments due to economic or insurance issues. The mortality rates of all patients one and 2 years after injury were 16.6 and 39.4\%, respectively. Of the 691 patients who did undergo surgical treatment, the mortality rates one and 2 years after injury were 12.0 and $35.7 \%$, respectively. Of the 116 patients with non-surgical treatments, the mortality rates one and 2 years after injury were 44.0 and $61.2 \%$, respectively. Thus, the surgical group had a significantly lower mortality rate $(p=0.001)$ (Table 1$)$.

The various factors that may affect mortality rates are shown in Table 2. One and 2 years after injury, the mortality was significantly higher in male patients $(p<0.001$, $p=0.001)$. The mortality rates were significantly higher one and 2 years after injury in the older aged group $(p<$ $0.001)$. The mortality rates at one and 2 years after injury were higher in the nonsurgical group $(p<0.001)$. The Kaplan-Meier survival analysis showed that the 5-year survival rate of the surgical group was $60.8 \%$ and that of the nonsurgical group was $31.3 \%$. Thus, the surgical group showed a higher survival rate (Fig. 1). The mortality rate at 1 year after injury of the lower ASA grade group was lower than that of higher ASA grade group $(p<0.001)$.

Data concerning fracture types and treatment options are shown in Table 3. According to the surgical methods, a statistically significant difference in mortality rates was observed for intertrochanteric fractures 1 year after fracture, but no significant difference in the mortality rates was observed between the two groups 2 years after fracture $(p=0.012, p=$ 0.519). In patients with femoral neck fracture, according to the surgical method, mortality rates at both one and 2 years after injury were not significantly different $(p=0.574, p=0.856)$. 
Table 1 Mortality rates of surgical and nonsurgical treatments

\begin{tabular}{lllll}
\hline & Total & Surgical treatment & Nonsurgical treatment & $p$ value \\
\hline Patient number & 807 & 691 & 116 & $51(44.4 \%)$ \\
Death 1 year after the traumatic event & $134(16.6 \%)$ & $83(12.0 \%)$ & $247(35.7 \%)$ & $71(61.2 \%)$ \\
Death 2 years after the traumatic event & $318(39.4 \%)$ & $<.001$ \\
\hline
\end{tabular}

The mortality rates of medical comorbidities are shown in Table 4 . The mortality rate 1 year after injury was significantly higher in patients with $\geq 3$ comorbidities than patients with less than three comorbidities $(p=0.001)$. In patients with associated comorbidities such as congestive heart failure, ischemic heart disease, dementia, chronic kidney disease, and cancer, the mortality rates one and 2 years after injury were significantly higher.
The predictors of mortalities 1 and 2 years after injury are shown in Table 5 . The mortality rate 1 year after injury was related to age, surgical treatment, ASA grades, the number of associated comorbidities, and smoking. By contrast, the mortality rate 2 years after injury was related to sex, age, and surgical treatment. Among the various factors, surgical treatment had the greatest effect on the mortality rate one and 2 years after injury (Odds ratio: 4.39 and Odds ratio: 2.52, respectively).

Table 2 Influencing factors associated with mortality 1 and 2 years after the traumatic event

\begin{tabular}{|c|c|c|c|c|}
\hline Factors & Death 1 year after traumatic event & $p$-value & Death 2 years after traumatic event & $\overline{p \text {-value }}$ \\
\hline$\overline{\text { Sex }}$ & & $<0.001$ & & 0.001 \\
\hline Female & $85(13.9 \%)$ & & $221(36.2 \%)$ & \\
\hline Male & $49(24.9 \%)$ & & $97(48.2 \%)$ & \\
\hline Age & & $<0.001$ & & $<0.001$ \\
\hline $65-75$ & $31(10.2 \%)$ & & $94(31 \%)$ & \\
\hline $75-85$ & $77(19.2 \%)$ & & $148(36.9 \%)$ & \\
\hline$>85$ & $26(25.2 \%)$ & & $56(54.4 \%)$ & \\
\hline Treatments & & $<0.001$ & & $<0.001$ \\
\hline Surgical & $83(12 \%)$ & & $247(35.8 \%)$ & \\
\hline Nonsurgical & $51(44 \%)$ & & $71(61.2 \%)$ & \\
\hline ASA grade & & $<0.001$ & & 0.081 \\
\hline I, II & $21(6.7 \%)$ & & $98(31.1 \%)$ & \\
\hline III, IV & $62(16.5 \%)$ & & 149 (39.6\%) & \\
\hline Fracture region of femur & & 0.886 & & 0.268 \\
\hline Neck & $64(16.4 \%)$ & & $146(37.4 \%)$ & \\
\hline Intertrochanteric & $70(16.8 \%)$ & & $172(41.3 \%)$ & \\
\hline Time to surgery & & 0.764 & & 0.615 \\
\hline$<5$ days & $19(15.8 \%)$ & & $46(38.3 \%)$ & \\
\hline$\geq 5$ days & $96(16.8 \%)$ & & $231(40.5 \%)$ & \\
\hline No. of comorbidity & & $<0.001$ & & 0.056 \\
\hline$<3$ & $104(14.8 \%)$ & & $269(38.2 \%)$ & \\
\hline$\geq 3$ & $30(29.4 \%)$ & & $49(48.0 \%)$ & \\
\hline Smoking History & & $<0.001$ & & 0.030 \\
\hline Smoking & $41(28.08 \%)$ & & 69 (47.26\%) & \\
\hline Non-smoking & 92 (13.94\%) & & $248(37.58 \%)$ & \\
\hline Insurance & & 0.004 & & 0.134 \\
\hline Medical insurance & $114(15.45 \%)$ & & 285 (38.62\%) & \\
\hline NMC & 20 (28.99\%) & & $33(47.83 \%)$ & \\
\hline
\end{tabular}




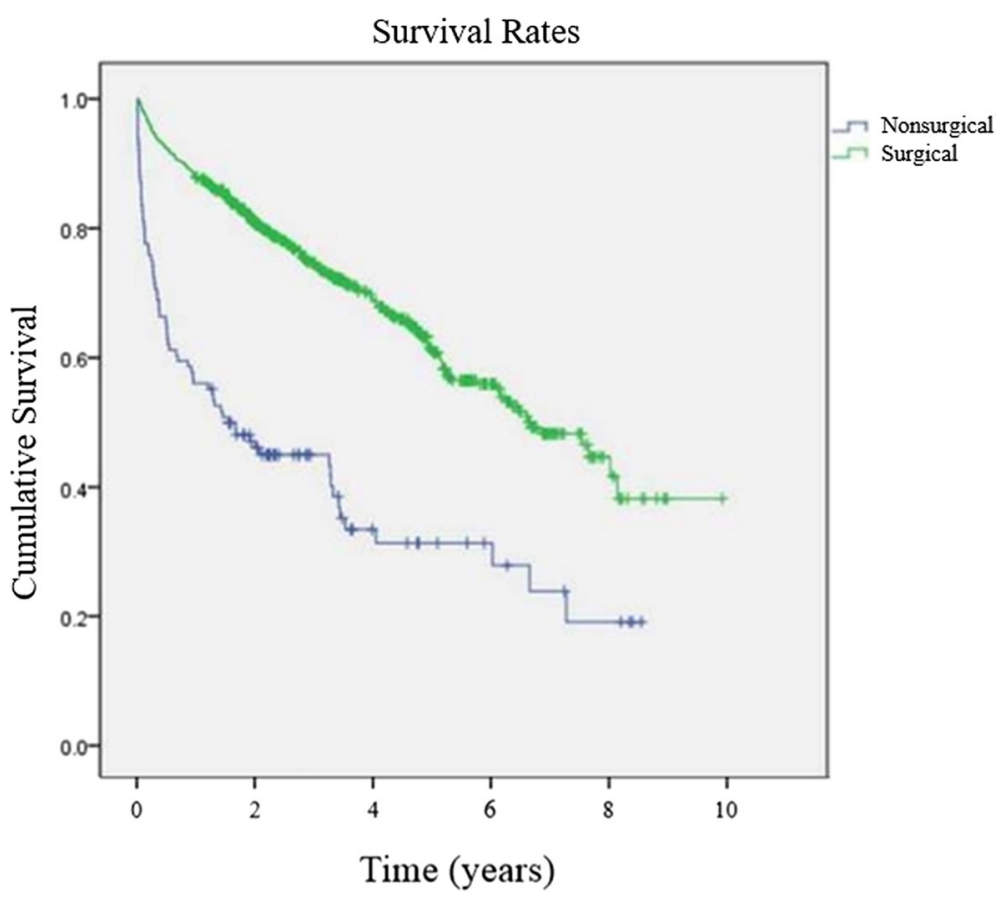

Fig. 1 Kaplan-Meier survival rates between surgical and nonsurgical treatment groups

\section{Discussion}

With the aging society, the elderly population is increasing, and the hip fractures in the elderly are gradually increasing. In elderly patients with osteoporosis, hip fractures are frequently the results of low-energy traumas such as falling on the ground. Hip fracture in the elderly is an important problem that can lead to death. Many studies reported the mortality rates of hip surgery after 1 year ranged from 12.7 to $29.2 \%$ [5-8]. In our study, the total mortality rate 1 year after injury was $16.6 \%$, similar to those reported previously. The mortality rates 1 year after surgery was $12.0 \%$ in surgical group

Table 3 Mortality rates of surgical techniques 1 and 2 years after the traumatic event

\begin{tabular}{|c|c|c|c|c|}
\hline Variables & $\begin{array}{l}\text { Death } 1 \text { year } \\
\text { after the } \\
\text { traumatic event }\end{array}$ & $p$-value & $\begin{array}{l}\text { Death } 2 \text { years } \\
\text { after the } \\
\text { traumatic event }\end{array}$ & $p$-value \\
\hline Neck fractures & & 0.574 & & 0.856 \\
\hline Arthroplasty & $41(13.2 \%)$ & & 105 (33.9\%) & \\
\hline Internal fixation & $3(9.7 \%)$ & & $10(32.3 \%)$ & \\
\hline $\begin{array}{l}\text { Intertrochanteric } \\
\text { fractures }\end{array}$ & & 0.012 & & 0.519 \\
\hline Arthroplasty & 22 (16.54\%) & & 53 (39.85\%) & \\
\hline Internal fixation & 17 (7.83\%) & & 79 (36.41\%) & \\
\hline Overall & & 0.017 & & 0.954 \\
\hline Arthroplasty & $63(14.2 \%)$ & & 158 (35.7\%) & \\
\hline Internal fixation & $20(8.1 \%)$ & & 89 (35.9\%) & \\
\hline
\end{tabular}

and $44.0 \%$ in nonsurgical group with significant difference. The overall mortality rate 2 years after injury was $39.4 \%$, and the mortality rates 2 years after injury were significantly different between surgical group and nonsurgical group. The mortality rates 1 year after injury was similar to that of the normal population [9], but the mortality rate 2 years after injury was higher than that 1 year after injury. We thought that these results were associated with various factors in elderly patients, such as age, sex, type of fractures, comorbidities, and surgical techniques.

Among the various factors related to mortality rate, age has been reported as one of the most influencing factors after hip fracture. Paksima et al. [3] and Miller [10] reported that the mortality rate increased with increasing age, but White et al. [9] and Cornwall et al. [11] found that the mortality rate and age showed an inverserelation (that the mortality rate does not differ with age). Our study showed higher mortality rates both one and 2 years after injury in patient $\geq 75$ years of age.

Based on gender, Kenzora et al. [12] reported no difference in the mortality rates between male and female patients. However, Miller [10] reported a higher mortality rate in male patients. In our multiple regression analysis, the mortality rate increased 2 years after injury only in male patients. However, this result may be associated with other factors such as the difference in average life expectancy of male and female patients. Therefore, mutiple factors should be analysed. 
Table 4 Mortality rates of medical comorbidities

\begin{tabular}{|c|c|c|c|c|c|}
\hline Medical comorbidity & Total & $\begin{array}{l}\text { Death } 1 \text { year after the } \\
\text { traumatic event }\end{array}$ & $p$-value & $\begin{array}{l}\text { Death } 2 \text { years after the } \\
\text { traumatic event }\end{array}$ & $p$-value \\
\hline$\overline{\mathrm{CHF}}$ & 42 & $16(38.1 \%)$ & $<0.001$ & $24(57.1 \%)$ & 0.016 \\
\hline $\mathrm{IHD}$ & 61 & $17(27.0 \%)$ & 0.021 & $26(41.3 \%)$ & 0.752 \\
\hline Dementia & 81 & $23(28.4 \%)$ & 0.003 & $49(60.5 \%)$ & $<0.001$ \\
\hline CKD & 31 & $11(35.5 \%)$ & 0.004 & $17(54.8 \%)$ & 0.073 \\
\hline DM & 239 & $38(15.9 \%)$ & 0.727 & 87 (36.4\%) & 0.257 \\
\hline Hypertension & 483 & $75(15.5 \%)$ & 0.316 & 189 (39.1\%) & 0.845 \\
\hline COPD & 95 & $21(22.1 \%)$ & 0.125 & $41(43.2 \%)$ & 0.426 \\
\hline Cancer & 38 & $20(52.6 \%)$ & $<0.001$ & $26(69.4 \%)$ & $<0.001$ \\
\hline LC & 12 & $3(25.0 \%)$ & 0.431 & $6(50.0 \%)$ & 0.449 \\
\hline RA & 22 & $2(9.1 \%)$ & 0.337 & $6(27.3 \%)$ & 0.238 \\
\hline Parkinson's disease & 11 & $1(9.1 \%)$ & 0.507 & $4(36.3 \%)$ & 0.842 \\
\hline
\end{tabular}

CHF congestive heart failure, IHD ischemic heart disease, CKD chronic kidney disease, DM diabetes mellitus, COPD chronic obstructive pulmonary disease, $L C$ liver cirrhosis, $R A$ rheumatoid arthritis

In general, intertrochanteric fracture was caused more frequently by higher energy trauma as compared with femoral neck fracture. Therefore, intertrochanteric fracture induces more bleeding and requires a longer operation time, more complicated surgical methods and requires avoiding full weight-bearing exercise after the operation. As a result, patients with intertrochanteric fracture showed a higher mortality rate than patients with femoral neck fracture [13-15]. However, there were also reports that there was no difference in mortality rates between the two fracture types $[12,15]$. In our study, there was no statistically significant difference in mortality rates according to type of fracture. In previous reports, Hossain et al. [16] reported that nonsurgical treatment can be an appropriate choice for patients who are not suitable for surgery after fracture, and no significant difference in mortality rates or functional results was observed between the surgical and nonsurgical groups. However, Yoon et al. [4] reported that the higher mortality rate in the nonsurgical group was caused by financial issues, and they showed a higher mortality rate and a serious loss of functions. In this study, significantly higher mortality rates were observed in the nonsurgical group one and 2 years after injury. In addition, results of multiple regression analysis indicated that surgery was the greatest factor affecting mortality rate.

According to surgical method employed, Garden [17] reported higher mortality rates for hemiarthroplasty than for internal fixation, however, Sikorski and Barrington [18] reported the opposite results. Several studies reported that there was no difference in mortality rates between surgical methods $[17,18]$. Hemiarthroplasty takes more time during surgery than internal fixation, and produces more bleeding, which leads to a higher acute mortality rate, but an advantage is that the non-weight-bearing period for fracture healing can be shortened. This study found a significantly higher mortality rate 1 year after injury for the hemiarthroplasty group, but no significant difference was revealed 2 years after injury. The reason for the higher mortality rate 1 year after injury is probably that

Table 5 Predictors of mortalities 1 and 2 years after the traumatic events

\begin{tabular}{|c|c|c|c|c|c|c|}
\hline \multirow[t]{2}{*}{ Factors } & \multicolumn{3}{|c|}{ Death 1 year after the traumatic event } & \multicolumn{3}{|c|}{ Death 2 years after the traumatic event } \\
\hline & $\mathrm{OR}$ & $95 \% \mathrm{Cl}$ & $p$-value & $\mathrm{OR}$ & $95 \% \mathrm{Cl}$ & $p$-value \\
\hline Male & 1.40 & $0.82-2.39$ & 0.217 & 1.60 & $1.06-2.40$ & 0.024 \\
\hline Age $\geq 75$ & 2.00 & $1.22-3.28$ & 0.006 & 1.52 & $1.09-2.13$ & 0.014 \\
\hline Surgical treatment & 4.39 & $2.61-7.35$ & 0.000 & 2.52 & $1.56-4.08$ & 0.000 \\
\hline ASA grade III, IV & 2.25 & $1.33-3.81$ & 0.003 & 1.35 & $0.96-1.89$ & 0.086 \\
\hline Neck fracture & 1.12 & $0.72-1.74$ & 0.608 & 0.93 & $0.67-1.28$ & 0.637 \\
\hline No. of comorbidity $\geq 3$ & 1.90 & $1.07-3.39$ & 0.030 & 1.39 & $0.85-2.28$ & 0.184 \\
\hline Smoking history & 2.00 & $1.14-3.53$ & 0.016 & 1.19 & $0.76-1.87$ & 0.454 \\
\hline Medical aid & 1.16 & $0.57-2.37$ & 0.683 & 0.89 & $0.49-1.63$ & 0.710 \\
\hline Time to surgery $\geq 5$ days & 1.00 & $0.56-1.78$ & 0.998 & 1.08 & $0.71-1.64$ & 0.708 \\
\hline
\end{tabular}

OR odds ratio, $\mathrm{Cl}$ confidence interval, ASA American Society of Anesthesiologists 
hemiarthroplasty was preferentially selected for patients of age $\geq 75$, when there was evidence of poor bone quality, and comminuted fractures were present.

Generally, hemiarthroplasty may not be appropriate for patients younger than 70 years, because of possibility of excessive degeneration of acetabular articular cartilage. This degenerative change increased the rate of revision surgery to as high as $26 \% 5$ years after surgery [19]. However, a recent big data research on femoral neck fractures conducted by Eskildsen et al. [20], showed that overall revision rates of hemiarthroplasty and total hip arthroplasty were similar in patients aged between 65 and 69 years. Blomfeldt et al. [21] reported that the bipolar hemiarthroplasty may be sufficient for elderly patients with lower functional demands, because the total hip arthroplasty results in increased blood loss and longer operating time. Therefore, we believe that hemiarthroplasty is a useful treatment option for the limited purposes in the frailest patients (ASA grade III/IV), even though the patients are under 70 years of age.

Although various factors affect mortality rate in hip fractures, many studies found the associated comorbidities were the key factor. Lehner et al. [22] reported that the mortality rate was higher in patients with two or more associated comorbidities. Kilci et al. [5] reported that the mortality rate increases with ASA grades and the number of comorbidities. Our study supported their findings on the baseline of 1 year after injury, but the mortality rate decreased to the level of normal population 2 years after injury. Other factors, like comorbidities and ASA grades may affect mortality rates. Regarding the results of mortality rate based on each comorbidity, several studies found that heart diseases are the greatest factor affecting mortality rate [23, 24]. In this study, patients with congestive heart failure, dementia, and cancer had higher mortality rates than those who did not have comorbidities. Patients with ischemic heart diseases and chronic kidney diseases had a higher mortality rate 1 year after injury, compared with patients who did not have such conditions. We did not find other comorbidities that affected the mortality rate.

Regarding the time from injury to operation, Zuckerman et al. [25] reported that the mortality rate 1 year after injury increased if the surgery was performed 3 days after injury. In this study, the patients were divided into two groups based on the five-day point after injury, we found the mortality rates one and 2 years after injury are similar in both groups. In this study, if the number of comorbidities was low $(<3)$, it was possible to perform the surgery within 5 days after injury, but more comorbidities are associated with more preoperative evaluations and examinations and prolonged time between injury and surgery. However, we were able to determine the exact status and mortality rates of the two groups.
Our study has some limitations. First, it is unable to determine the direct relations between hip fracture and the cause of death because many difficulties exist. Second, accurate comparative analysis was impossible because of the too small a number of patients in nonsurgical group. Third, multiple bias may exist based on a single-center observation. This is not a blinded study, and the patients were not randomly allocated.

\section{Conclusions}

In elderly patients with hip fractures, surgical treatments can decrease the mortality rate compareing with nonsurgical treatments. In addition, patients who had three or more comorbidities (heart disease, chronic renal failure, dementia, and history of cancer) are associated with a higher risk of mortality.

\section{Abbreviation \\ ASA: American Society of Anesthesiologists}

Acknowledgements

Not applicable

\section{Authors' contributions}

KTH: Writing the manuscript, analysing and interpreting the data. JKM: Analysing and interpreting the data. YHK: Designing the study, analysing and interpreting the data. All authors read and approved the final manuscript.

\section{Funding}

No funding to declare.

\section{Availability of data and materials}

The datasets used and/or analysed during the current study are available from the corresponding author on reasonable request.

Ethics approval and consent to participate

Not applicable

Consent for publication

Not applicable

Competing interests

The authors declare that they have no competing interests.

Author details

${ }^{1}$ Department of Orthopedic Surgery, Hanyang University Hospital, 222 Wangsimni-ro, Seongdong-gu, Seoul 133-791, South Korea. ${ }^{2}$ Department of Orthopedic Surgery, Hanyang University Guri Hospital, Gyomoon-dong 249-1, Guri city, Gyunggi-do 471-701, South Korea.

Received: 5 April 2019 Accepted: 19 July 2019

Published online: 01 October 2019

\section{References}

1. Ju DG, Rajaee SS, Mirocha J, Lin CA, Moon CN. Nationwide analysis of femoral neck fractures in elderly patients: a receding tide. J Bone Joint Surg Am. 2017:99:1932-40.

2. Pedersen AB, Ehrenstein V, Szepligeti SK, Lunde A, Lagerros YT, Westerlund A, Tell GS, Sorensen HT. Thirty-five-year trends in first-time hospitalization for hip fracture, 1-year mortality, and the prognostic impact of comorbidity: a Danish Nationwide cohort study, 1980-2014. Epidemiology. 2017;28:898-905.

3. Paksima N, Koval KJ, Aharanoff G, Walsh M, Kubiak EN, Zuckerman JD, Egol KA. Predictors of mortality after hip fracture: a 10-year prospective study. Bull NYU Hosp Jt Dis. 2008;66:111-7. 
4. Yoon BH, Baek JH, Kim MK, Lee YK, Ha YC, Koo KH. Poor prognosis in elderly patients who refused surgery because of economic burden and medical problem after hip fracture. J Korean Med Sci. 2013;28:1378-81.

5. Kilci O, Un C, Sacan O, Gamli M, Baskan S, Baydar M, Ozkurt B. Postoperative mortality after hip fracture surgery: a 3 years follow up. PLoS One. 2016;11:e0162097.

6. Guerra MT, Viana RD, Feil L, Feron ET, Maboni J, Vargas AS. One-year mortality of elderly patients with hip fracture surgically treated at a hospital in southern Brazil. Rev Bras Ortop. 2017;52:17-23.

7. Wang AQ, Ng BH, Cheung LP, Chin RP. Factors affecting mortality and hospital admissions after hip surgery among elderly patients with hip fracture in Hong Kong - review of a three-year follow-up. Hong Kong J Occup Ther. 2017;30:6-13.

8. Aharonoff GB, Koval KJ, Skovron ML, Zuckerman JD. Hip fractures in the elderly: predictors of one year mortality. J Orthop Trauma. 1997:11:162-5.

9. White BL, Fisher WD, Laurin CA. Rate of mortality for elderly patients after fracture of the hip in the 1980. s J Bone Joint Surg Am. 1987;69:1335-40

10. Miller CW. Survival and ambulation following hip fracture. J Bone Joint Surg Am. 1978;60:930-4.

11. Cornwall R, Gilbert MS, Koval KJ, Strauss E, Siu AL. Functional outcomes and mortality vary among different types of hip fractures: a function of patient characteristics. Clin Orthop Relat Res. 2004:425:64-71.

12. Kenzora JE, McCarthy RE, Lowell JD, Sledge CB. Hip fracture mortality. Relation to age, treatment, preoperative illness, time of surgery, and complications. Clin Orthop Relat Res. 1984;186:45-56.

13. Frisch NB, Wessell N, Charters M, Greenstein A, Shaw J, Peterson E, Trent Guthrie S. Hip fracture mortality: differences between intertrochanteric and femoral neck fractures. J Surg Orthop Adv. 2016;27:64-71.

14. Cameron ID, Chen JS, March LM, Simpson JM, Cumming RG, Seibel MJ, Sambrook PN. Hip fracture causes excess mortality owing to cardiovascular and infectious disease in institutionalized older people: a prospective 5-year study. J Bone Miner Res. 2010;25:866-72.

15. Sheikh HQ, Hossain FS, Aqil A, Akinbamijo B, Mushtaq V, Kapoor H. A comprehensive analysis of the causes and predictors of 30-day mortality following hip fracture surgery. Clin Orthop Surg. 2017;9:10-8.

16. Hossain M, Neelapala V, Andrew JG. Results of non-operative treatment following hip fracture compared to surgical intervention. Injury. 2009:40:418-21.

17. Garden RS. Selective surgery in medial fractures of the femoral neck: a review. Injury. 1977;9:5-7.

18. Sikorski JM, Barrington R. Internal fixation versus hemiarthroplasty for the displaced subcapital fracture of the femur. A prospective randomised study. J Bone Joint Surg Br. 1981;63-B:357-61.

19. Zhao Y, Fu D, Chen K, Li G, Cai Z, Shi Y, Yin X. Outcome of hemiarthroplasty and total hip replacement for active elderly patients with displaced femoral neck fractures: a meta-analysis of 8 randomized clinical trials. PLoS One. 2014;9:e98071

20. Eskildsen SM, Kamath GV, Del Gaizo DJ. Age matters when comparing hemiarthroplasty and total hip arthroplasty for femoral neck fractures in Medicare patients. Hip Int. 2018:1120700018816924. https://journals. sagepub.com/doi/pdf/10.1177/1120700018816924.

21. Blomfeldt R, Tornkvist H, Eriksson K, Soderqvist A, Ponzer S, Tidermark J. A randomised controlled trial comparing bipolar hemiarthroplasty with total hip replacement for displaced intracapsular fractures of the femoral neck in elderly patients. J Bone Joint Surg Br. 2007:89:160-5.

22. Sexson SB, Lehner JT. Factors affecting hip fracture mortality. J Orthop Trauma. 1987:1:298-305.

23. Eiskjaer S, Gelineck J, Søballe K. Fractures of the femoral neck treated with cemented bipolar hemiarthroplasty. Orthopedics. 1989:12:1545-50.

24. Panula J, Pihlajamaki H, Mattila VM, Jaatinen P, Vahlberg T, Aarnio P, Kivela SL. Mortality and cause of death in hip fracture patients aged 65 or older: a population-based study. BMC Musculoskelet Disord. 2011;12:105.

25. Zuckerman JD, Skovron ML, Koval KJ, Aharonoff G, Frankel VH. Postoperative complications and mortality associated with operative delay in older patients who have a fracture of the hip. J Bone Joint Surg Am. 1995;77:1551-156.

\section{Publisher's Note}

Springer Nature remains neutral with regard to jurisdictional claims in published maps and institutional affiliations.

\section{Ready to submit your research? Choose BMC and benefit from:}

- fast, convenient online submission

- thorough peer review by experienced researchers in your field

- rapid publication on acceptance

- support for research data, including large and complex data types

- gold Open Access which fosters wider collaboration and increased citations

- maximum visibility for your research: over $100 \mathrm{M}$ website views per year

At BMC, research is always in progress.

Learn more biomedcentral.com/submissions 